\title{
Urdimento
}

Revista de Estudos em Artes Cênicas

E-ISSN: 2358.6958

\section{a_ponte: cena do teatro universitário: \\ Fronteiras e movências de uma experiência em processo}

Galiana Brasil

\section{Para citar este artigo:}

BRASIL, Galiana. a_ponte: cena do teatro universitário:

Fronteiras e movências de uma experiência em processo.

Urdimento, Florianópolis, v. 1, n. 40, mar./abr. 2021.

do) DOI: http:/dx.doi.org/10.5965/1414573101402021e0114

Este artigo passou pelo Plagiarism Detection Software | iThenticate 
a_ponte: cena do teatro universitário:

Fronteiras e movências de uma experiência em processo

Galiana Brasil ${ }^{1}$

\title{
Resumo
}

Este trabalho buscou revelar modos de fazer, interseções, fronteiras e derivas de uma experiência de arte e curadoria: a_ponte: cena do teatro universitário, a partir das possibilidades de diálogo entre campos da pedagogia, das artes cênicas e da gestão cultural, visando além da construção de memória e compartilhamento, a possibilidade de futuros possiveis para uma experiência em curso, profundamente atravessada e impactada pelo contexto atual, o cenário da pandemia de covid-19 no ano de 2020.

Palavras-chave: Curadoria. Currículo. Pedagogia. Teatro universitário.

a_ponte : cena do teatro universitário:

Frontiers and movements of an in-process experience

\begin{abstract}
This work sought to reveal ways of doing, intersections, boundaries and branches of an experience of art and curation: a_ponte: university theater scene, from the possibilities of dialogue between fields of pedagogy, scenic arts and cultural management, aiming beyond the construction of memory and sharing, the possibility of possible futures for an ongoing experience, deeply affected and impacted by the current situation, the scenario of the COVID-19 pandemic in 2020.
\end{abstract}

Keywords: Curatorship. Curriculum. Pedagogy. University theater.

a_ponte : cena do teatro universitário:

Fronteras y movimientos de una experiencia en proceso

\section{Resumen}

Este trabajo trató de revelar modos de hacer, intersecciones, limites y derivas de una experiencia de arte y curadoria: a_ponte escena teatral universitaria, a partir de las posibilidades de diálogo entre los campos de la pedagogía, las artes escénicas y la gestión cultural, apuntando allá de la construcción de la memoria, la posibilidad de futuros posibles para una experiencia profundamente impactada por el contexto actual, el escenario de la pandemia de COVID 19 em el año 2020.

Palabras clave: Curadoría. Curriculum. Pedagogía. Teatro universitario.

\footnotetext{
${ }^{1}$ Gestora do núcleo de artes cênicas do Itaú Cultural. Graduada em Educação Artística pela Universidade Federal de Pernambuco (UFPE). Especialista em ensino da arte (UFPE), e em literatura brasileira e interculturalidade pela Universidade Católica de Pernambuco. Possui produção teórica no campo dos estudos culturais a partir do teatro, da gestão cultural, do currículo e do ensino de artes. Mestranda profissional da Célia Helena Centro de Artes e Educação/ São Paulo (SP). galianabrasil@gmail.com

(9) http://lattes.cnpq.br/0110708329339509 iD https://orcid.org/0000-0001-6678-5670
} 
Para início de conversa...

tudo que está em você não sabe que é seu.

( Prof. Dudude Herrmann)

É possível apreender uma experiência em processo? Quando se intenta não apenas fotografar, mas suspender o momento para aprender com ele - das suas potências, fragilidades e, nesse movimento, cavar, perscrutar, em busca de espaços e campos abertos para diálogos, suturas, intervenções - abrimo-nos em certa exposição, nos colocamos em dada perspectiva, em uma zona de fronteira, de não-lugar, ou, ainda, em um lugar não nomeado, vazio, à espera de sentido.

Uma experiência em processo é algo como uma espiral que não se apreende de forma linear, algo que começa antes do início e que insiste em reverberar: rastros, resíduos, espécie de poeira cósmica que não deixa o acontecimento adormecer. O mundo hoje, tal como se apresenta, não contribui muito para que tenhamos experiências. Sim, experimentamos, passamos por coisas, consumimos um tanto de informação, mas a experiência, como nos mostra Jorge Larrosa Bondia (2002), requer um tanto de passividade, exposição, a que estamos cada vez mais desacostumadas/os e que, nos dias de hoje, torna-se "quase impossível", pois

[...] requer parar para pensar, parar para olhar, parar para escutar, pensar mais devagar, parar para sentir, sentir mais devagar, demorar-se nos detalhes, suspender a opinião, suspender o juízo, suspender a vontade, suspender o automatismo da ação, cultivar a atenção e a delicadeza, abrir os olhos e os ouvidos, falar sobre o que nos acontece, aprender a lentidão, escutar aos outros, cultivar a arte do encontro, calar muito, ter paciência e dar-se tempo espaço (Bondia, 2002, p. 24).

A mim encanta a provocação de Bondia, alimentando o desejo de ir de encontro aos encontros, desafiando as armadilhas do mundo que nos empurra ao capacitismo, ao consumismo, a toda sorte de excessos (informações, virtualidades), para arriscar uma pausa para o acometimento da experiência. Convite que nos impele, ainda, a pensar espaços de respiros, uma ação de 
encontros estendidos, na cidade cujo lema é não parar, a forjar uma sesta em conjunto, colaborativa, em que o menos se converta em mais, em que o processo seja protagonista e que a construção de vínculos nos dê a ver a construção de uma comunidade, ainda que temporária, embaçando fronteiras entre gestão e pedagogia, curadoria e currículo, estética e ética, aquilo que chamamos de mercado e o que conhecemos por fazer amador.

A experiência nos convida à exposição, a um certo pacto com o risco. E que não se confunda sua necessidade de suspensão, tempo, escuta, com algo parecido com o sossego, pois não se trata disso. Olhemos a etimologia da palavra, de origem latina: o ex, exterior, estrangeiro, somado ao periri, periculum, perigo. Nas línguas latinas (assim como nas germânicas) a experiência carrega, ladeadas, as dimensões de perigo e travessia (Bondia, 2002, p. 25).

\section{mote da prosa}

Como protagonista deste estudo, apresentamos a_ponte: cena do teatro universitário, um projeto de gestão cultural que desenvolvo desde 2018 encampado pela instituição onde atuo como gestora das artes cênicas - o Itaú Cultural - na cidade de São Paulo, juntamente com tudo que determina, compõe e deriva de uma ação como esta: processo seletivo e maratona de apresentação das obras, somados àquelas ações que generalizamos como formativas: mesas, oficinas, debates... em suma, ações de fruição e intercâmbios.

De forma singular em relação à maioria dos festivais existentes hoje no Brasil, a_ponte traz desde seu enunciado o interesse pela cena universitária, repercutindo a essência do teatro amador, em especial o legado do movimento do teatro estudantil iniciado nos anos 1930 vinculado à figura icônica do ator e teatrólogo Paschoal Carlos Magno (1906-1980), que criou em 1938, no Rio de Janeiro, o Teatro do Estudante do Brasil (TEB), um marco histórico para esse movimento, como aponta a professora Fabiana Siqueira Fontana (2009), pesquisadora da trajetória de Magno, que credita a este grupo amador a institucionalização da categoria do 
teatro universitário no Brasil.

Precursor da engenharia - hoje quase banal - de fazer circularem grupos e espetáculos de diversos sítios do país - em que pese o desafio logístico dessa malha nos anos 1940. Sem dúvida, um trabalho desbravador ao qual todes nós que atuamos nessa cadeia hoje - artistas, gestoras/es, públicos - somos tributárias/os. Magno captava recursos e se utilizava de sua influência de embaixador para negociar com governos, prefeituras e produzir circulação e encontros de grupos amadores de norte a sul do Brasil.

Interlocutor e parceiro de Magno atuando em Pernambuco, o dramaturgo, crítico e encenador Hermilo Borba Filho (1917-1976), em fins de 1945, assumia a direção do Teatro do Estudante de Pernambuco. Magno e Filho foram grandes entusiastas e incentivadores desse nicho do teatro amador brasileiro. Desenvolveram projetos de difusão e contribuíram para o amadurecimento e para a repercussão de um teatro fora dos ditames comerciais que vingavam à época.

Filho atuou ainda fortemente na busca da modernização dos palcos brasileiros, iluminando uma dramaturgia que florescia na Europa e suas reverberações em nossos palcos. Para o desenvolvimento de uma cena que não fosse a réplica do frívolo teatro burguês, o encenador apontava a força e a relevância da cena estudantil, como nos aponta o pesquisador Luís Reis (2008), escavando a ação reformadora do referido encenador:

Mais livres da preocupação com a bilheteria, caberia aos amadores e aos estudantes trazerem aos espectadores brasileiros peças desses autores modernos que as companhias profissionais, em sua maioria especializadas em comédias ligeiras ou dramalhões, ainda não tinham interesse em encenar (Reis, 2008, p. 28).

Eis um grande legado do teatro realizado pelos estudantes, que se conecta, em sua prática, a toda diversidade e desigualdade de recursos materiais que existe nas distintas realidades das instituições brasileiras. A tese de Filho continua fazendo sentido e poderia ser refinada, adaptando-se aos contextos de nossa época, mas se mantendose em essência. Livres das armadilhas do mercado 
profissional, os estudantes têm mais compromisso em fazer ecoar suas vozes, as agruras de seu tempo, que com agradar ou com tentar se fazer compreender por instituições e por certo distinto público.

Decerto, as pautas e o mundo em que estão inseridas/os as/os estudantes de hoje diferem um tanto daqueles dos anos 1940, mas o espírito inquieto e buliçoso da juventude - oxalá nunca se acabe - segue atravessando os tempos. Rememorando Paulo Freire, em seu diálogo com Antonio Faundez em Por uma pedagogia da pergunta (2011, p. 75), "[...] a existência humana implica assombro, pergunta e risco, e, por tudo isso, implica ação, transformação."

Ao mencionar generalidades como "pautas" e "mundo" atual, sinto necessidade de deslocar - e de nomear - alguns contextos como preponderantes para o debate e para a movência desse recorte universitário sob o qual estamos trabalhando. O ano é 2020. Pós cotas, pós políticas de afirmação e de reparação de injustiças históricas, assim como pós novos retrocessos, movimentos de censura e levantes conservadores, e em plena pandemia mundial do COVID-19.

Portanto, assim como a cena teatral difere bastante daquela dos 1940, podemos afirmar que as salas de aula são outras, também. Então não custa anunciar que questões étnico-raciais, de gênero e de território fazem parte do rolê. É sobre isso(s). Sempre que nos referirmos às possibilidades de experiência, intentamos promover ações decolonizadas; cada vez que trouxermos à baila as questões pedagógicas - em especial as práticas curriculares -, é com o intuito de detonar as práticas hegemônicas, de ver florescer epistemologias até então invisibilizadas; todas as vezes que refletirmos sobre curadoria, reafirmamos a necessidade de um exercício curatorial que opere em caráter divergente das assimetrias historicamente construídas.

Buscamos a concepção de exercícios que iluminem a cosmogonia do povo negro, a sabedoria dos originários, a ética feminista, a contemporaneidade da cultura popular, que embaralhem a noção de centro-periferia, que ressaltem o poder das margens e das bordas, das singularidades de gênero, em especial das pessoas trans. Essa miríade de significados constitui uma espécie de ética que, 
para ser exercida, precisa que se estabeleçam bases estruturais e que se trabalhe pela ruptura de estruturas dominantes que cultivam a segregação; afinal, como nos lembra Freire (2011, p. 54) "a ideologia é algo muito concreto" e, sobre o conceito de ruptura,

Acredito que aprendemos, através das rupturas, que a grande lição da vida está em que a vida é uma corrente de rupturas, uma ruptura que precisa ser destruída, para ser superada, e essa nova ruptura tem de ser superada por uma outra ruptura (Freire, 2011, p. 52).

Assim, entendemos a importância de atentarmos às necessidades de cada edição d' a_ponte em conexão com as/os estudantes, para que haja criticidade e engajamento e, sempre que necessário, reposicionamento e ação dialógica. A filósofa e educadora estadunidense bell hooks reposicionou em seu trabalho práticas e referências do educador Paulo Freire - sua maior inspiração para uma educação libertária -, em virtude das questões de raça e gênero ausentes ou enviesadas no conjunto da obra freireana. É inevitável que, mesmo sendo o patrono da educação brasileira e referência mundial em pedagogia crítica, um homem não negro, cisgênero, nascido nos anos 1920 no Nordeste brasileiro, carregue consigo as contradições de seu tempo.

A síntese desse bom combate, nas palavras de hooks (2020, p. 31):

No curto período que estudei com ele fui profundamente tocada por sua presença, pelo modo que sua maneira de ensinar exemplifica sua teoria pedagógica. [...] Minha experiência com ele me devolveu a fé na educação libertadora.

Longe de aprofundar as singularidades desse encontro, gostaria tão somente de registrar o tanto de ensinamento que podemos extrair da relação dialógica que hooks escolhe estabelecer com esse mestre, tão diverso dela em tantas questões. Em uma época em que vivemos a ditadura dos cancelamentos e das polarizações, ler Freire pelas lentes da hooks - mulher negra, feminista, ativista completamente vocacionada para a pedagogia, declarademente apaixonada pela experiência da sala de aula - tem sido uma grande inspiração para pensar a pedagogia dos processos de curadoria e seus atravessamentos na construção de uma espécie de 
sala de aula expandida ou, quem sabe, de um palco-escola em que processos de arte e vida convivam em retroalimentação, na busca de outros futuros. Afinal,

Apesar de graves retrocessos, houve e continuará havendo mudanças construtivas radicais na maneira como ensinamos e aprendemos, uma vez que mentes "em busca de liberdade" ensinam a transgredir e a transformar (hooks, 2020, p. 59).

\section{Curadoria é afeto}

Quando falamos em curadoria - como tantos conceitos no universo da cultura - nem toda a compreensão está dada. Sua origem, por exemplo, remonta a uma função específica vinculada às artes visuais; porém, sua expansão foi tanta na segunda metade do século XX, que tanto o exercício como a figura de quem atua em curadoria vazaram dos salões de artes, das bienais, das mostras e das exposições, espraiando-se em todas as linguagens artísticas, orquestrando e posicionando toda sorte de programação.

Do parco terreno das certezas, a de que, definitivamente, é uma esfera de trabalho legitimado na contemporaneidade (Obrist, 2010), em que o campo é o grande espaço de formação - uma espécie de tautologia, visto que é um ofício aprendido na lida. Outra certeza, a de que há pouca literatura produzida e que a as publicações ainda concentram-se na experiência eurocêntrica e no campo das artes visuais, porém, no tocante às artes cênicas, aqui no Brasil, nota-se o movimento de espaços de formação e produção teórica, em especial pela escala crescente de cursos e ações formativas ligadas ao campo da gestão cultural.

Ao calibrar nossas lentes para investigar práticas curatoriais no universo das artes cênicas, destacamos os festivais como o grande campo de experimentação e de formação desta curadoria. São, a um só tempo, territórios de ação e de produção de saberes. Não raramente a maioria dessas mostras produzem revistas, catálogos ou cadernos, forjando espaços de crítica e de reflexão não restrita à cena, trazendo também as questões contemporâneas que as estimulam e as atravessam, registrando e produzindo memória através de artigos e entrevistas 
nos mais distintos territórios.

Os festivais podem ser lidos como comunidades de aprendizagem, o que difere bastante de uma ação eventual, sem construção de vínculos com o lugar que o abriga e com as pessoas que nele tomam parte - embora isso seja algo que também possa ocorrer em festivais. É triste quando percebemos que um festival cai de paraquedas em uma cidade, como uma espécie de vitrine de loja por vezes muito harmônica, perfumada, mas cujas roupas não vestem as pessoas do lugar, ou, antes, cabem apenas em algumas pessoas com medidas muito específicas, restringindo o diálogo àqueles que dominam seus códigos de acesso.

Em defesa de uma pedagogia crítica e engajada, bell hooks (2020, p. 48) nos conta que jamais inicia um processo pedagógico "sem antes criar as bases para construir uma comunidade". Penso que isso sirva de pressuposto para uma curadoria que considere contextos, que se firme a partir da relação com o território que a abriga. Considerar contextos e vínculos, olhar interessada e honestamente para as pessoas envolvidas no processo é um caminho possível para assegurar a possibilidade da experiência. Esse objetivo central, estruturante, tem início antes mesmo do processo de seleção, porque essa "conta" não deve ser depositada somente na aposta do que encontraremos no processo. Todo esse movimento começa no olho de quem vê. Formar uma banca, ou uma equipe de seleção é tarefa relevante e determinante para qualquer processo de curadoria.

Em verdade, o exercício de exclusão já se inicia aí, em decorrência disso que chamamos de representatividade. Para que a diversidade de corpos, saberes e vozes não seja restringida a temas e discursos, ela precisa se fazer carne nas estruturas de poder, ela precisa estar marcada nos corpos de quem encarna processos de escolha. Também isso é pensar a curadoria com um olhar decolonial em consonância com as urgências e os apelos do nosso tempo, mirando a possibilidade de um futuro menos adoecido que o presente que nos rege, em que a barbárie reina encarnada no genocídio das populações negra, trans e indígena, na misoginia e no feminicídio.

Decorre também daí minha defesa por um trabalho de gestão cultural - que 
inclui a curadoria - feito em campo. Há que se levantar da cadeira e comer um bocado de poeira real para que se conheça outras realidades, para que sejamos experiência. Não existe receita, tutorial ou bibliografia alguma que dê conta de ensinar a viver na pele de outra pessoa, mas é sempre e cada vez mais necessária a cessão de espaço (privilégio) e a possibilidade de compartilhamento, de construção conjunta. Como nos lembra hooks (2020, p. 73),

Colaborar com diferentes pensadores para trabalhar em busca de uma compreensão mais ampla de raça, gênero e classe é essencial àqueles que desejam se mover para além dos formatos unidimensionais de pensamento, de existência e de vida.

O oco do currículo

No campo complexo da estrutura educacional o currículo figura como uma fonte abundante de estudos. Situa-se no centro da política escolar, influenciando práticas pedagógicas, definindo sistemas avaliativos. Tratase de um elemento intrínseco ao processo educativo, carregado de significados ao longo do tempo (Brasil, 2005, p. 10).

Com essa citação iniciava, em 2005, o trabalho de conclusão da especialização em Ensino de Artes, no departamento de Teoria da Arte da Universidade Federal de Pernambuco. Revolvo esses escritos, levantando uma poeira que nunca adormecera completamente, para legitimar uma certa obsessão por essa prática discursiva no campo da pedagogia do teatro e por tudo que disso deriva: o que selecionamos para dar a ver e por que. Ou, antes (e sempre): o que fica de fora - e por que.

Em 2005 minha pesquisa se dava na tríade Educação de Jovens e Adultos (EJA) / Currículo / Arte. Interessava-me problematizar o lugar da arte em um estudo de caso em educação de jovens e adultos. Hoje, quase duas décadas depois, me vejo novamente enredada nas teias curriculares, mirando em perspectiva para o projeto cultural já citado aqui, a_ponte: mostra da cena universitária. 
O projeto rebentou em janeiro de 2018, com uma mostra de trabalhos selecionados no ano anterior, a partir de convocatória pública. O chamamento era direcionado a estudantes de todo território nacional, vinculados a instituições de ensino superior de artes - técnico ou universitário -, para que se inscrevessem cenas ou montagens finais de cursos ou disciplinas, visando a seleção para uma mostra. Para além dos exercícios cênicos de dez grupos selecionados - com representação das cinco regiões do país - oficina de crítica, intercâmbios, rodas de debates sobre os espetáculos e mais uma série de atividades coexistiram durante os dez dias da mostra.

No ano seguinte, a presença de 10 docentes vinculadas/os às instituições e grupos selecionados, acompanhando a mostra, demandou mergulhos paralelos e novos cruzamentos para dar conta de absorver e de projetar uma série de problematizações, em diferentes perspectivas. Se o dizer freireano "a cabeça pensa onde o pés pisam" nos lembra que contextos e territórios são matérias definidoras do processo pedagógico, testemunhamos o quanto a diversidade de realidades se fazia presente naquele pequeno universo. Entretanto, diante das tantas diferenças, havia algo que interseccionava e igualava práticas e instituições tão diversas: a percepção das ausências, em especial, no tocante às matrizes curriculares.

Tal percepção se adiantava diante de nós, em momento anterior a esse encontro, ainda na fase de seleção dos trabalhos. Na segunda edição da mostra, a equipe reunida para debater os trabalhos se perguntava, por exemplo: onde estaria a produção de teatro para crianças, pois se repetia o baixo número de inscrições dessa natureza que havíamos encontrado na primeira edição. A falta de conexão dos trabalhos com os contextos de seus territórios de origem também era observada. A sensação de que tudo era muito parecido, em termos de temáticas e de referencial teórico declarado, confirmava a tese hegemônica curricular vigente, deixando pouco ou nenhum espaço para saberes divergentes.

No atual contexto de distanciamento social, vimos na edição de 2020 a possibilidade de uso das plataformas virtuais para dar conta de amplificar o alcance d'a_ponte, através de salas expandidas de aprendizagem, norteadas por 
questionamentos nascidos nas percepções das ausências curriculares previamente diagnosticadas. Não tencionamos, diante desse problema, oferecer respostas, pois entendemos que é o problema que move e alimenta a necessidade da pesquisa. As perguntas são motores geradores de reflexão, as perguntas são a origem do conhecimento, nos ensina Freire para quem a pergunta é condição de processo de aprendizagem "Saber perguntar-se, saber quais são as perguntas que nos estimulam e estimulam a sociedade" (Freire, 2011, p. 71).

Traduzimos nossas inquietações em cinco questões: 1. Dramaturgias: a palavra é plural? 2. Discurso e práxis para uma cena Queer: é possível falar de cena Queer? 3. O figurino e a maquiagem são marginais na criação? 4. Corpo e voz: que corpo é possível na virtualidade? 5. Quem tem medo do teatro para crianças? Essas foram as cinco salas expandidas para as quais convocamos as/os estudantes que comporiam esta edição do projeto.

Nesse microuniverso das cinco duplas, conseguimos diversidade de região, gênero e formação/atuação, assim como forjamos encontros entre profissionais que até então não haviam atuado em parceria. Nossa intenção aqui não é avaliar esse processo, isto será feito em nova produção escrita, mais adiante, mas ensaiar um mergulho anterior a esse procedimento - que inclusive possa lhe trazer perspectivas instauradoras -, iluminar esse processo de concepção das salas como um exercício de curadoria plasmado no momento atual, atravessado pela dor e pela dureza de uma pandemia. Um processo de curadoria que olhou para as práticas curriculares a partir das práticas discursivas das experiências anteriores, problematizando a construção de narrativas e disputa de subjetividades, intentando inaugurar um espaço de encontro com novos cruzamentos, capaz de reverberar e de nos guiar em construções que nos apontem o futuro deste projeto.

Convidamos dez docentes-artistas para guiarem o processo pedagógico, uma dupla por sala, para que houvesse troca, atrito e complementaridade de pontos de vista desde a partida. Questões em torno de território, raça e gênero já se manifestaram nessa primeira curadoria. Essas parcerias trouxeram novos olhares, algumas perguntas sofreram ajustes de texto e discursos e, assim, desenhamos nossa contribuição para esse debate matricial na rede de formação das artes 
cênicas. Além das salas expandidas, abrimos uma chamada para pesquisas artigos, trabalhos de conclusão de curso em artes da cena, cujas pesquisas possibilitassem leituras e diálogos com as temáticas/perguntas abertas nas salas virtuais. A intenção é, mais adiante, cruzar esse resultado com os movimentos gerados nas salas e inaugurar novos territórios de encontros, espaços de compartilhamento, fruição, friç̧ão e, oxalá, novas possibilidades de alumbramentos e de experiências.

Seguimos na tentativa de estender o sentido e o alcance das práticas curriculares, fugindo do entendimento histórico que lhes limita o sentido ao de seleção de conteúdos para, diferentemente, entende-las como polifonia de vozes, territórios e biomas. Ouçamos a sabedoria indígena que nos ensina que a humanidade é palavra em pé, assim, as estruturas que operam - subvertem ou mantêm os sistemas - são espécies de organismos curriculares também. Tal percepção nos ajuda a entender as instituições, os organismos promovedores como estruturas vivas e como parte do processo cultural, com ação crítica e responsável, livrando qualquer viés messiânico tão venenoso à cadeia criativa.

\section{Isto não é uma conclusão}

Estamos em um momento muito delicado em que a demanda por interação virtual tem concentrado nossas formas de encontro, o que reforça ainda mais o tamanho do abismo das desigualdades sociais vigentes no país. Afinal, a disponibilidade de hardware, de algum domínio da tecnologia e de uma certa capacidade de conexão para trabalhar, estudar e fruir espetáculos, já risca no chão uma separação imensa - mais uma - entre pessoas mais privilegiadas economicamente e aquelas cujo acesso à comunicação virtual é nulo ou muito limitado por razões de classe ou quaisquer outras, em um tempo em que essa virtualidade não é apenas questão de escolha, mas, muitas vezes, condição inescapável.

Realizar a_ponte nesse contexto, durante o ano de 2020, foi um grande desafio não somente pelas questões de acesso ditadas pela virtualidade, mas, 
também, porque esse é um projeto que traz o encontro como propósito. Ele se faz meio para que haja junções, rejuntes, amálgamas convertidos para a primeira linguagem que apreendemos: a corporal. Sabemos que há muitos ganhos, muita potência nessa experiência em rede. Certamente carregaremos muito desse formato e algumas de suas frentes devem permanecer em edições futuras, mas é importante reafirmar a vocação que esse projeto tem - seu propósito - fazendo jus ao legado voltado para uma arte do encontro, da presença, na celebração de toda a materialidade dos diferentes biomas encarnados.

Ver a diversidade presente por alguns dias, em ajuntamento, suas cenas e danças, ouvir suas vozes ecoando nos espaços é uma aula expandida de brasilidade, é a promoção de uma poética outra: a pedagogia dos sotaques, o currículo dos corpos, a curadoria dos territórios, a cena dos afetos.

As perguntas levantadas nas salas virtuais seguem carregadas de sentido; ainda que gerando respostas provisórias, são também perguntas mediadoras, enunciados que se deslocam, que se encarnam em práticas, em sujeites, em culturas. São setas lançadas na relação entre discentes, docentes e artistas. Continuam reverberando, como em suspensão, nos mostrando caminhos, trilhas e acessos. Precisaremos de muita escuta para entendermos o que nos sopram, que direção seguir.

Estamos, todes, em um momento de suspensão. Mais do que arriscar respostas, precisamos aprender a entender as delicadezas, as urgências, as singularidades do momento para aprender com ele. Parece que mais do que nunca estamos, todes, na condição de alunes. Que o excesso de virtualidade, tantos estímulos e informações não nos endureça, não nos adormeça os sentidos. Que possamos regar na virtualidade a potência do encontro para que logo quando ele possa acontecer sejamos inteiras, inteiros, que haja novas perguntas, assombro e risco. 


\section{Referências}

BONDIA, Larrosa Jorge. Notas sobre a experiência e o saber da experiência. Trad. João Wanderley Geraldi. Revista Brasileira de Educação, Rio de Janeiro, n. 19, 2002.

BRASIL, Galiana Galindo. O lugar da arte no currículo da EJA do SESC Casa Amarela. 2005. Monografia (Especialização em arte) - Universidade Federal de Pernambuco, Recife, 2005.

FONTANA, Fabiana Siqueira. Teatro, cultura e estado: Paschoal Carlos Magno e a fundação do Teatro do Estudante do Brasil. 2009. Dissertação (Mestrado em Artes Cênicas) - Universidade Federal do Estado do Rio de Janeiro, Rio de Janeiro, 2009.

FREIRE, Paulo e FAUNDEZ, Antonio. Por uma pedagogia da pergunta. Revisão técnica e tradução do texto de Antonio Faundez, Heitor Ferreira da Costa. 7a. ed. Ver., ampl. e atual. - São Paulo: Paz e Terra, 2011.

HOOKS, Bell. Ensinando pensamento crítico: sabedoria prática. Trad. Bhuvi Libânio. São Paulo: Elefante, 2020.

HOOKS, BELL. Ensinando a transgredir. a educação como prática de liberdade. Trad. Marcelo Brandão Cipolla. São Paulo: Martins Fontes, 2020.

OBRIST, Hans Ulrich. Uma breve história da curadoria. Trad. Ana Resende. São Paulo: BEl Comunicação, 2010

REIS, Luis Augusto da Veiga Pessoa. Fora de cena no palco da modernidade: um estudo do pensamento teatral de Hermilo Borba Filho. 2008. Tese (Doutorado em Letras) - Universidade Federal de Pernambuco, Recife, 2008.

Recebido em: 12/01/2021 Aprovado em: 19/04/2021 